\title{
Endoscopic Biopsy Technique using an Alcohol Swab to Prevent Transmission through the Instrument Channel in the COVID-19 Era
}

\author{
Shusei Fukunaga, Taku Manabe, Mitsuhiro Kono, Tadashi Ochiai, Akira Higashimori, Masaki Ominami, Yasuaki Nagami and \\ Yasuhiro Fujiwara \\ Department of Gastroenterology, Osaka City University Graduate School of Medicine, Osaka, Japan
}

According to reports, the potential transmission routes of the Coronavirus Disease 2019 (COVID-19) infection include contact, droplet, and airborne transmission. ${ }^{1,2}$ Therefore, many strategies to reduce aerosol spread by patient coughs during endoscopy have been reported, such as plastic cube barrier, vinyl-box, modified surgical mask, and glove-covered mouthpiece. ${ }^{3-6}$ Endoscopic biopsy for suspected malignancies should be performed for diagnosis confirmation even in the COVID-19 era. ${ }^{7.8}$ However, to our knowledge, there are no reports of precautions focusing on potential contamination during biopsy. First, a patient's contaminated fluids, which potentially exist in the instrument channel of the endoscope, could splash from the biopsy valve on the channel port into the endoscopist's face. Moreover, infection risk is higher because of the close distance to the endoscopist's face. ${ }^{9}$ Second, it should also be considered that long and elastic biopsy forceps have an unexpected risk of contact transmission when the forceps are pulled out from the channel port. Here, we present a method without harmful effects of using an alcohol swab not only to prevent contaminated fluid splash during biopsy, but also to deactivate severe acute respiratory syndrome coronavi-

\footnotetext{
Received: December 22, 2020 Revised: January 24, 2021

Accepted: February 1, 2021

Correspondence: Yasuaki Nagami

Department of Gastroenterology, Osaka City University Graduate School of Medicine, 1-4-3, Asahimachi, Abeno-ku, Osaka 545-8585, Japan

Tel: +81-6-6645-3811, Fax: +81-6-6645-3813, E-mail: yasuaki-75@med.osaka-cu. ac.jp

ORCID: https://orcid.org/0000-0002-4617-2188
}

(c) This is an Open Access article distributed under the terms of the Creative Commons Attribution Non-Commercial License (http://creativecommons.org/ licenses/by-nc/3.0) which permits unrestricted non-commercial use, distribution, and reproduction in any medium, provided the original work is properly cited. rus 2 (SARS-CoV-2) for the reduction of contact transmission after biopsy. We performed a demonstration to inspect the protective effect of the swab using an upper gastrointestinal training simulator (LM-022; KOKEN CO., LTD., Tokyo, Japan) and fluorescent dye (see Supplementary Video 1).

The first demonstration shows the endoscopic biopsy procedure using a training simulator without precaution for potential contamination. After the forceps were pulled out by an assistant, many fluorescent dye droplets were identified on the right forearm, chest, neck, and mask of the endoscopist by illuminating with ultraviolet light (Fig. 1A, B).

Next, we present the alcohol swab technique during biopsy to reduce contamination. Ahead of biopsy, an alcohol swab package was placed with a cellophane tape near the instrument channel port in order to quickly obtain the swab (Fig. $2 \mathrm{~A})$. The endoscopist removes the swab and continues to hold down the top of the biopsy valve, "sandwiching" the forceps to stabilize until the forceps are slowly pulled out by an assistant (Fig. 2B).

The last demonstration shows the endoscopic biopsy procedure with an alcohol swab. After the assistant pulled out the forceps, the fluorescent dye was absorbed in the swab. Ultraviolet light illumination revealed no scattering of dye on the endoscopist.

For further clinical examination, we evaluated the aerosol spread using the portable HHPC6 + Handheld Particle Counter (Beckman Coulter, Inc., Brea, CA, USA), while actual biopsies were performed using esophagogastroduodenoscopy (EGD). This device was positioned at the face height of the endoscopist and recorded the quantity of particles (0.3-2.0 $\mu \mathrm{m})$ per cubic feet every 5 seconds in order to verify the en- 


\section{Ce cuncan enooscopy}
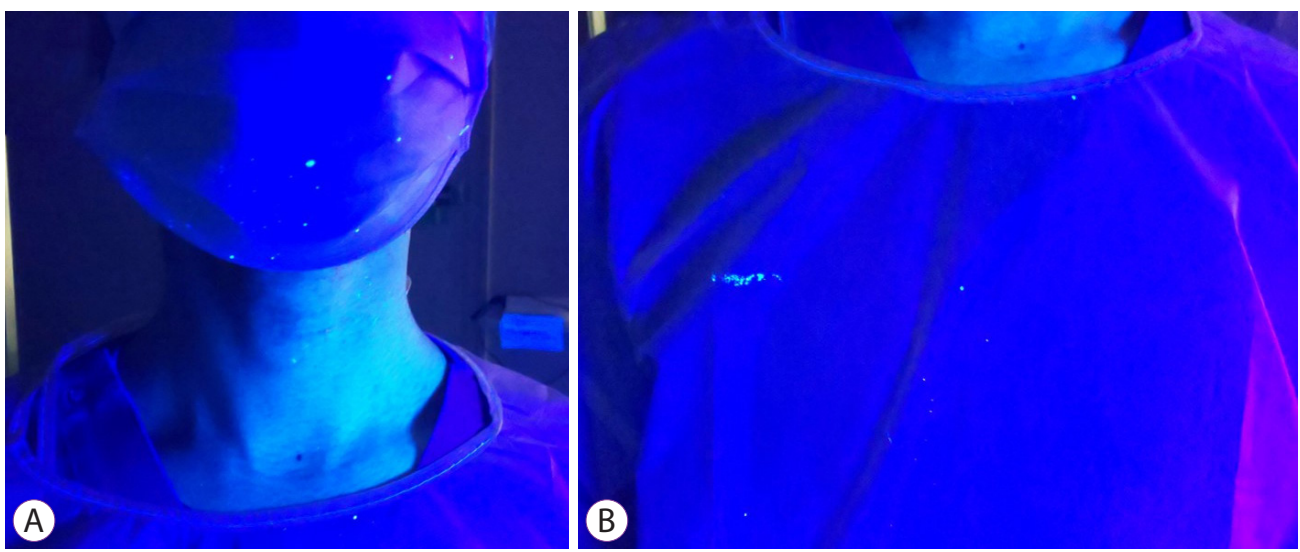

Fig. 1. (A) Droplets of fluorescent dye illuminated with ultraviolet light identified on the neck and mask of an endoscopist. (B) Droplets of fluorescent dye found on endoscopist's chest.
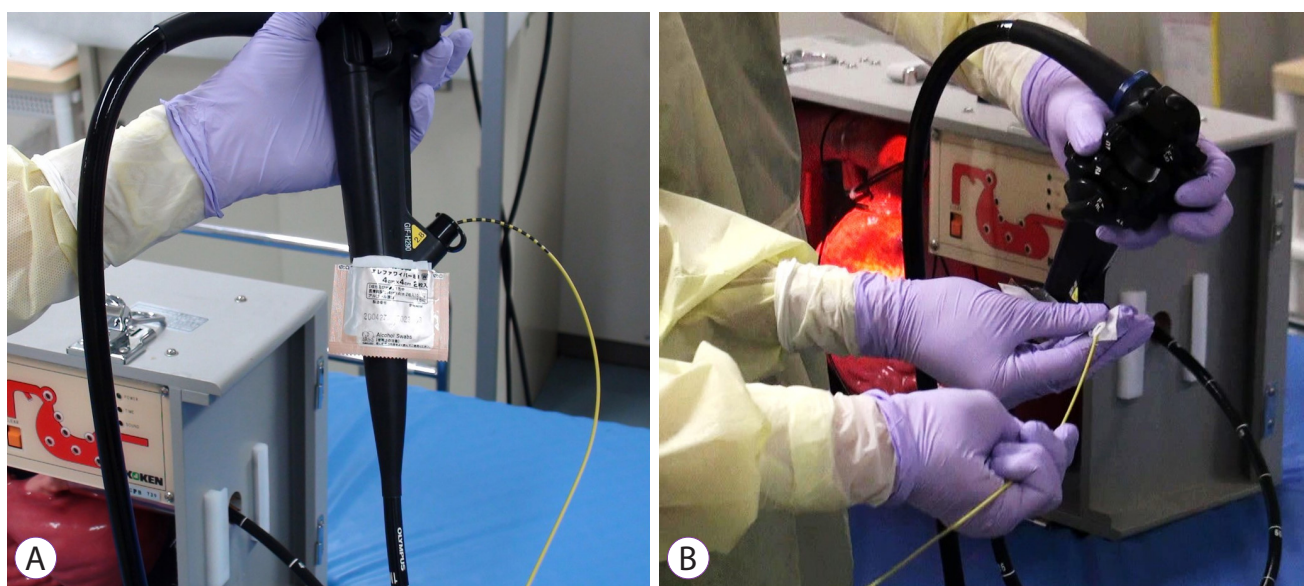

Fig. 2. (A) Ahead of biopsy, an alcohol swab package taped near the instrument channel port. (B) The endoscopist continues to hold down the top of the biopsy valve, "sandwiching" the forceps by the swab to stabilize until the forceps are slowly pulled out by an assistant.

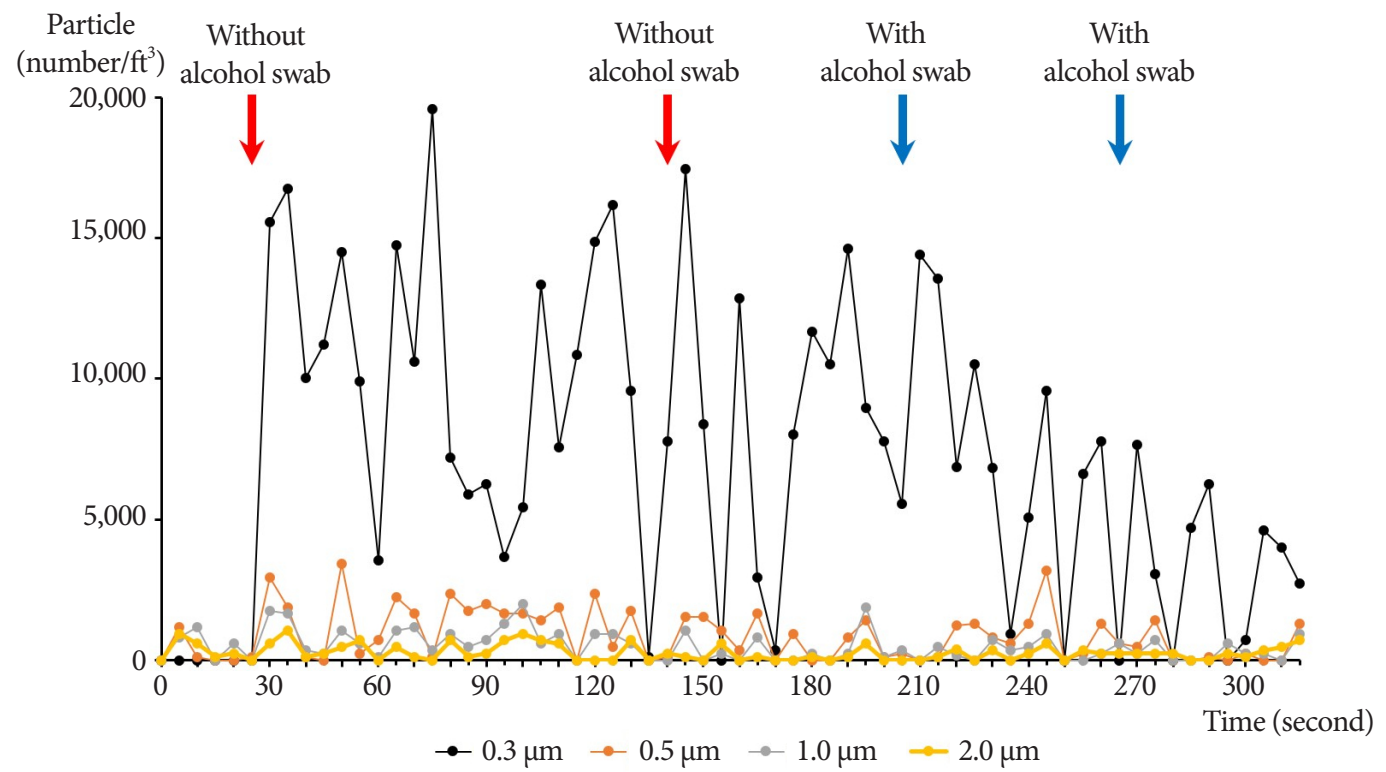

Fig. 3. The temporal changes of particle counts in each size per cubic feet during esophagogastroduodenoscopy. The red and blue arrows are the timing of biopsies without and with alcohol swab, respectively. 
doscopist's exposure to the aerosol. All values were normalized against the background particle count in the endoscopy room at the start of measurement. Fig. 3 shows the temporal changes in particle counts for each size during EGD. Most notably, the quantity of particles $(0.3 \mu \mathrm{m})$ did not increase after the biopsy with alcohol swab compared to that without alcohol swab. The total number of particles $(0.3-2.0 \mu \mathrm{m})$ measured for $30 \mathrm{~s}$ after two biopsies while using the alcohol swab was reduced to $59.4 \%$ compared to that without the alcohol swab $\left(94,470 / \mathrm{ft}^{3}\right.$ and $\left.159,060 / \mathrm{ft}^{3}\right)$.

Our demonstration using the simulator and fluorescent dye suggested that the alcohol swab technique could prevent contaminated fluid splash and contact with SARS-CoV-2 on the forceps. In particular, we believe that droplet infection via the instrument channel can be almost completely controlled by this technique. However, this simulation did not demonstrate the preventive effect of small aerosol particles that cause airborne infections. Therefore, using a particle counter, we showed that our alcohol swab technique could limit the spread of aerosol to approximately $60 \%$ during endoscopic biopsies; however, the actual protective effect against airborne SARSCoV-2 infection remains to be ascertained. Additional experiments are needed to investigate the effects of alcohol swabs on the disinfection of SARS-CoV-2 and the prevention of contact transmission. However, we consider that alcohol swabs can inactivate SARS-CoV-2 more effectively than simple gauze because of the disinfection effect of ethanol itself. ${ }^{10}$ Our technique using an alcohol swab, an easy, low-cost option, can prevent viral transmission by the avoidance of fluid and aerosol blowout from the channel and by disinfection of the forceps. This technique can be applied to any endoscope or a similar device. Therefore, a further protective effect might be obtained for essential endoscopic procedures during the COVID-19 pandemic, and this novel technique can be accepted as a standard precaution to ensure infection control during routine endoscopy even after the COVID-19 era.

\section{Conflicts of Interest}

The authors have no potential conflicts of interest.

Funding
None.

Author Contributions

Conceptualization: Shusei Fukunaga, Taku, Manabe, Yasuaki Nagami

Data curation: Akira Higashimori
Formal analysis: AH, SF

Investigation: SF, Taku Manabe, Tadashi Ochiai, Mitsuhiro Kono, Masaki Ominami

Methodology: SF, YN

Project administration: SF, YN

Supervision: Yasuhiro Fujiwara

Validation: $\mathrm{SF}, \mathrm{YN}, \mathrm{AH}$

Writing-original draft: $\mathrm{SF}$

Writing-review\&editing: YN

$\begin{array}{ll}\text { ORCID } & \\ \text { Shusei Fukunaga: } & \text { https://orcid.org/0000-0002-9336-8271 } \\ \text { Taku Manabe: } & \text { https://orcid.org/0000-0003-2884-5294 } \\ \text { Mitsuhiro Kono: } & \text { https://orcid.org/0000-0002-0811-2395 } \\ \text { Tadashi Ochiai: } & \text { https://orcid.org/0000-0003-3557-5472 } \\ \text { Akira Higashimori: } & \text { https://orcid.org/0000-0002-9950-9899 } \\ \text { Masaki Ominami: } & \text { https://orcid.org/0000-0002-9692-0420 } \\ \text { Yasuaki Nagami: } & \text { https://orcid.org/0000-0002-4617-2188 } \\ \text { Yasuhiro Fujiwara: } & \text { https://orcid.org/0000-0002-1225-1785 }\end{array}$

Supplementary Material

Video 1. A new method using an alcohol swab to reduce contamination during biopsy and simple demonstrations using fluorescent dye to inspect the protective effect. (https://doi.org/10.5946/ce.2021.027.v001).

\section{REFERENCES}

1. Huang C, Wang Y, Li X, et al. Clinical features of patients infected with 2019 novel coronavirus in Wuhan, China. Lancet 2020;395:497-506.

2. Morawska L, Cao J. Airborne transmission of SARS-CoV-2: the world should face the reality. Environ Int 2020;139:105730.

3. Sagami R, Nishikiori H, Sato T, Murakami K. Endoscopic shield: barrier enclosure during the endoscopy to prevent aerosol droplets during the COVID-19 pandemic. VideoGIE 2020;5:445-448.

4. Kobara H, Nishiyama N, Masaki T. Shielding for patients using a single-use vinyl-box under continuous aerosol suction to minimize SARS-CoV-2 transmission during emergency endoscopy. Dig Endosc 2020;32:e114-e115.

5. Maruyama H, Higashimori A, Yamamoto K, et al. Coronavirus disease outbreak: a simple infection prevention measure using a surgical mask during endoscopy. Endoscopy 2020;52:E461-E462.

6. Sasaki S, Nishikawa J, Sakaida I. Use of a Glove-Covered Mouthpiece during Upper Endoscopy to Prevent COVID-19 Transmission. Clin Endosc. 2021;54:289-290.

7. Soetikno R, Teoh AYB, Kaltenbach T, et al. Considerations in performing endoscopy during the COVID-19 pandemic. Gastrointest Endosc 2020;92:176-183.

8. Han J, Kim EY. Sharing our experience of operating an endoscopy unit in the midst of a covid-19 outbreak. Clin Endosc 2020;53:243-245.

9. Benter T, Klühs L, Teichgräber UK, Riechert F, Ludwig WD, Dörken B. Need for safety goggles for endoscopy. Endoscopy 2003;35:803.

10. Kampf G, Todt D, Pfaender S, Steinmann E. Persistence of coronaviruses on inanimate surfaces and their inactivation with biocidal agents. J Hosp Infect 2020;104:246-251. 